\title{
Acne in South African black adults: A retrospective study in the private sector
}

\author{
T P Zulu, ${ }^{1}$ BSc, MB ChB, FC Derm (SA), MMed; A Mosam, ${ }^{1}$ MB ChB, FC Derm (SA), MMed, PhD; Y Balakrishna, ${ }^{2}$ MSc (Statistics); \\ N C Dlova, ${ }^{1} \mathrm{MB} \mathrm{ChB}, \mathrm{FC}$ Derm (SA), PhD \\ ${ }^{1}$ Department of Dermatology, School of Clinical Medicine, Nelson R Mandela School of Medicine, College of Health Sciences, \\ University of KwaZulu-Natal, Durban, South Africa \\ ${ }^{2}$ Biostatistics Unit, South African Medical Research Council, Durban, South Africa
}

Corresponding author: T P Zulu (tpzulu@gmail.com)

Background. Acne vulgaris is the most common skin disorder affecting teenagers and young adults, and is becoming increasingly common in middle-aged women. It affects all skin types and ethnic groups, but dark-skinned individuals are burdened by post-inflammatory hyperpigmentation (PIH) as a sequela. PIH causes distress in acne patients even after the inflammatory lesions have resolved.

Objective. To describe the characteristics of acne in black South African adults in the private health sector in Durban, KwaZulu-Natal Province. Methods. A retrospective study of records of patients attending two large private dermatology clinics in central Durban, mainly catering for black patients, was performed. Data were collected for the period January - December 2014. Records with acne as a diagnosis were retrieved and analysed with regard to age, demographics, type and severity of acne, therapy, HIV status and outcomes.

Results. Of a total of $\sim 3000$ charts available for the 12-month period, 242 had acne as a diagnosis and were retrieved and analysed. Of these patients, $204(84.3 \%)$ were female and the remainder were male. The mean age was 28.5 years (under-18s were excluded from the study). Inflammatory acne was the most frequently encountered form (58.6\%). Fifteen patients (6.2\%) were on topical treatment only, and 226 (93.4\%) were on topical plus systemic treatment. PIH was the most common sequela ( $81.0 \%$ of patients).

Conclusions. The majority of the patients were young females with inflammatory acne, and PIH was the most common sequela. Early and vigorous treatment of acne may minimise its complications, including those seen mainly in black patients.

S Afr Med J 2017;107(12):1106-1109. DOI:10.7196/SAMJ.2017.v107i12.12419

Acne vulgaris is a disorder of the pilosebaceous unit that affects areas with a high density of sebaceous glands, i.e. the face, chest and back. It is a multifactorial disorder induced by hormonal changes, excessive sebum production, fluctuation of resident micro-organisms and accumulation of dead skin cells in hair follicles. ${ }^{[1-3]}$ This dysregulation results in the non-inflammatory lesions (comedones), inflammatory lesions (papules and pustules) and acne conglobate (nodules and cysts) seen in acne.

Acne is the most common skin disorder diagnosed by dermatologists and other healthcare providers worldwide, and mostly affects adolescents. ${ }^{[4-8]}$ The worldwide prevalence is $\sim 9.4 \%$. In adolescents, the prevalence is $65-75 \% \%^{[1,2]}$ In Durban, South Africa (SA), with a population of 2.901 million, ${ }^{[9]}$ it has been documented as the second most common skin disease, with females mainly affected $(1.75: 1) .^{[10,11]}$ Although acne has traditionally been thought to be a disorder of teenagers and adolescents, children and adults have been noted to be increasingly affected. ${ }^{[3-5,12,13]}$

Scarring and post-inflammatory hyperpigmentation (PIH) are the main sequelae of acne. The effects of PIH have mainly been documented in black patients, as PIH is most common in darkskinned individuals. Many patients seek therapy for PIH even after the active lesions have resolved. ${ }^{[7,8,14,15]}$

Widespread use of antibiotics has raised concerns regarding resistance in Propionibacterium acnes and other host commensals. ${ }^{[10]}$ Oral antibiotics should only be used at the beginning of treatment, for as short a time as possible, in combination with a non-antibiotic topical agent. Many patients experience flare-ups after cessation of successful therapy, making maintenance therapy necessary even during remission. ${ }^{[11,12]}$ Appropriate skin care should be integrated into the management of acne to help minimise recurrence. ${ }^{[12]}$ This underlines the importance of early diagnosis to prevent complications and reduce the financial and psychological costs, which can be significant. The cost of acne therapy has been calculated as up to USD350 - 870 per patient per year in the USA. ${ }^{[2]}$ No comparable data on acne costs are available for SA.

The presence of acne, particularly in adolescents, can negatively affect quality of life, self-esteem and mood. Suicidal ideation has been documented in $\sim 7.1 \%$ of affected individuals. ${ }^{[4]}$ This further illustrates the importance of early and aggressive treatment.

There are no studies specifically describing acne in black patients in the private health sector in SA.

\section{Objective}

To describe acne in black adults in Durban, KwaZulu-Natal Province, SA.

\section{Methods}

This was a retrospective review of records of black patients attending two private dermatology clinics in Durban over a 12-month period (January - December 2014, inclusive). The two clinics serve the majority of black patients seeking private dermatological treatment in Durban ( 8 000 patients per annum).

Inclusion criteria were: (i) a diagnosis of acne; and (ii) black African patients. Exclusion criteria were: (i) ethnic groups other than 
black African; (ii) age < 18 years; and (iii) non-South African patients. Age, gender, spectrum and severity of disease, therapeutic modalities, HIV status and treatment outcomes were analysed.

\section{Statistical analysis}

Sample size was calculated using Stata 14 (StataCorp, USA). Data analysis was performed by the Division of Biostatistics, South African Medical Research Council, and results were presented as frequencies and percentages for discrete data and means with standard deviations (SDs) for continuous data.

\section{Ethical approval}

Ethical approval was obtained from the University of KwaZulu-Natal Biomedical Research Institutional Review Board (ref. no. BE 283/15).

\section{Results}

Of the charts reviewed over the 12-month period, 242 fulfilled the inclusion criteria and were therefore retrieved for analysis (Table 1).

There were more females in the study cohort $(84.3 \%)$ than males (15.7\%). Nearly two-thirds of the patients had a tertiary education. The majority of the patients (93.4\%) received topical plus systemic treatment, with $97.5 \%$ showing improvement. Of the cohort, $6.6 \%$ were HIV-positive.

Fig. 1 shows the breakdown of the types of acne seen in the study (inflammatory, non-inflammatory, steroid-induced and other types). Inflammatory acne was the commonest type in this patient cohort $(58.6 \%)$, followed by non-inflammatory acne $(23.6 \%)$ and steroid-induced acne (8.6\%). Other types of acne were seen in $9.5 \%$ of patients.

Fig. 2 shows the severity of acne in the patient cohort, categorised by the clinician as mild, moderate, severe and unspecified at the time

\begin{tabular}{|c|c|}
\hline \multicolumn{2}{|c|}{$\begin{array}{l}\text { Table 1. Demographic characteristics of patients with acne } \\
(N=242) \text {, source of referral, HIV status, therapy and outcome }\end{array}$} \\
\hline \multicolumn{2}{|r|}{ 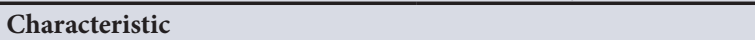 } \\
\hline \multicolumn{2}{|l|}{ Gender, $n(\%)$} \\
\hline Male & $38(15.7)$ \\
\hline Female & $204(84.3)$ \\
\hline \multicolumn{2}{|l|}{ Source of referral, $n(\%)$} \\
\hline General practitioner & $115(47.5)$ \\
\hline Self & $127(52.5)$ \\
\hline \multicolumn{2}{|c|}{ Highest qualification, $n$ (\%) } \\
\hline Primary & $9(3.7)$ \\
\hline Secondary & $55(22.7)$ \\
\hline Tertiary & $128(52.9)$ \\
\hline Postgraduate & $8(3.3)$ \\
\hline Unspecified & $42(17.4)$ \\
\hline \multicolumn{2}{|l|}{ HIV status, $n(\%)$} \\
\hline Positive & $16(6.6)$ \\
\hline Negative & $19(7.9)$ \\
\hline Unknown & $207(85.5)$ \\
\hline \multicolumn{2}{|l|}{ Treatment, $n(\%)$} \\
\hline Topical & $15(6.2)$ \\
\hline Topical plus systemic & $226(93.4)$ \\
\hline Other & $1(0.4)$ \\
\hline \multicolumn{2}{|l|}{ Outcome, $n(\%)$} \\
\hline Improvement & $236(97.5)$ \\
\hline No improvement & $1(0.4)$ \\
\hline Defaulted & $5(2.1)$ \\
\hline Age (yr), mean (range) & $28.5(18-59)$ \\
\hline
\end{tabular}

of diagnosis. Most of the patients (73.1\%) had moderate acne at time of diagnosis, $13.6 \%$ had mild acne and $10.8 \%$ had severe acne.

Fig. 3 displays the sequelae of acne in the patient cohort, i.e. PIH and other (keloids and scarring). Over $80 \%$ of patients had PIH. Just over $2 \%$ had other sequelae such as scarring and keloids.

\section{Discussion}

This study of black patients with acne in Durban documents characteristics of the most common skin disorder in the largest population group in SA. The mean age of the patients was 28.5 years. Studies have shown acne mainly to affect teenagers and young adults (65-75\%), sometimes persisting into the $30 \mathrm{~s}^{[2,11-15]}$ The prevalence is highest in the age group 16 - 19 years, with $\sim 20 \%$ of cases persisting beyond the age of $20 .^{[5]}$

Social development and considerable self-image awareness during adolescence means that acne can cause cosmetic concerns in this age group that may lead to significantly low self-esteem. However, our study shows that acne also affects adults into middle age, as has been documented by others. ${ }^{[1,7,8]}$ Females mainly appeared to be affected, with a female/male ratio of $\sim 5: 1$, although this could be because females are more likely than males to consult a dermatologist for a skin condition. Other studies have documented a female/male ratio of 2:1. ${ }^{[16]}$

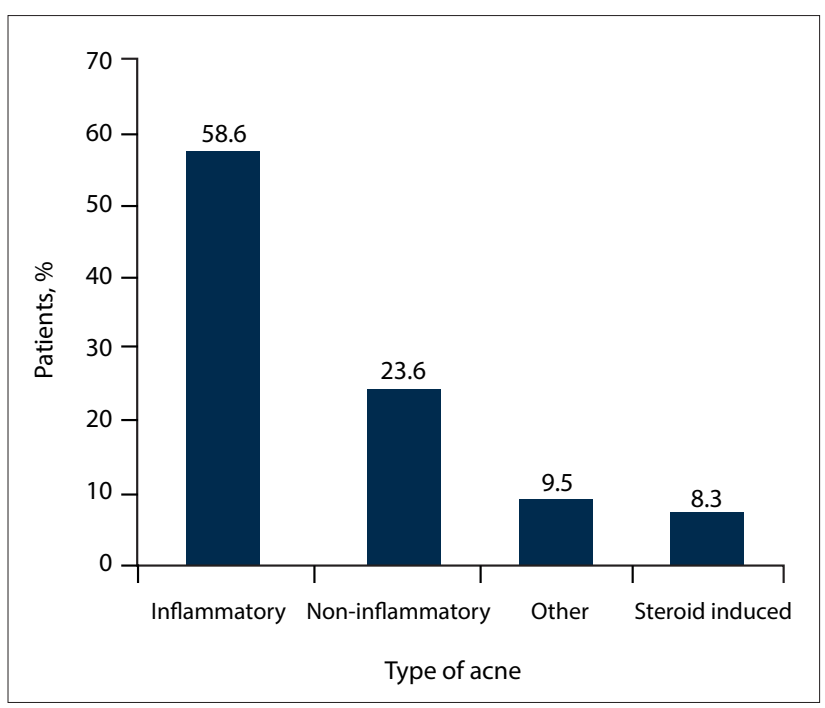

Fig. 1. Spectrum of acne according to clinical type in black patients attending two private dermatology clinics.

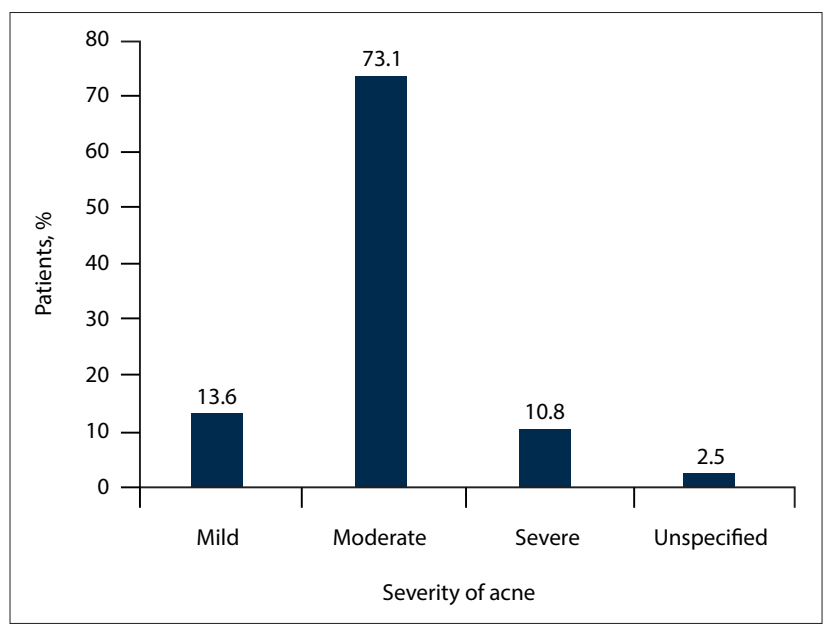

Fig. 2. Severity of acne in black patients attending two private dermatology clinics. 


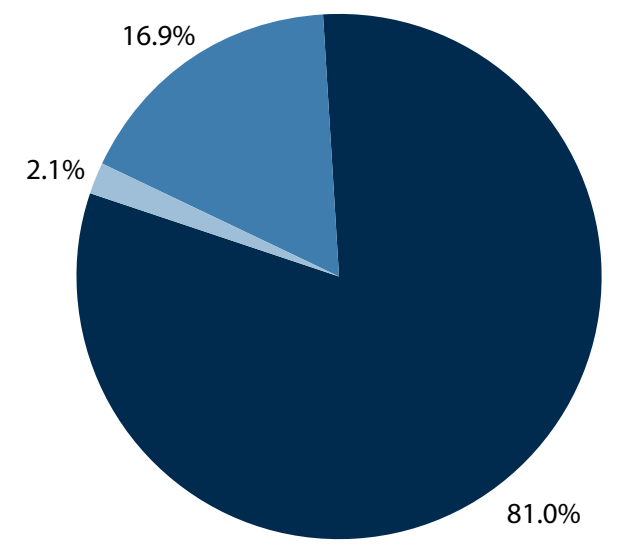

PIH Other None

Fig. 3. Complications of acne in black patients attending two private dermatology clinics. $(\mathrm{PIH}=$ post-inflammatory hyperpigmentation. $)$

A significant proportion of the patients in our study (52.5\%) were self-referred. This may be linked to the relatively high level of education of the study cohort, $56.2 \%$ of whom had a tertiary or postgraduate qualification, which indirectly translates to being able to afford to see a private dermatologist. The high number of selfreferrals could also be a result of failure of a primary healthcare provider to control the acne.

HIV infection has been documented in patients with acne. ${ }^{[5,17]}$ In our cohort $6.6 \%$ patients $(n=16)$ were documented to be HIVpositive. Four of these patients $(25.0 \%)$ had nodulocystic acne, which has previously been reported in HIV-positive individuals but can also be seen in those who are HIV-negative. ${ }^{[15]}$

Inflammatory acne was the most frequently observed type in our cohort, as has been documented in several other studies. ${ }^{[6,13-16,18]}$ The significant proportion of our patients with steroid-induced acne (8.3\%) may be due to the widespread abuse of skin-lightening agents containing cortisone, ${ }^{[19]}$ to which individuals living in Durban have easy access in the marketplace. In a 2006 Nigerian study, ${ }^{[8]} 45.3 \%$ of patients had steroid-induced acne following cosmetic use of topical corticosteroids. Other studies have reported prevalences of up to $45 \% \cdot{ }^{[3,20,21]}$ These cases were associated with both topical corticosteroid abuse for skin lightening in black patients, and anabolic steroids used by body builders.

Most of the patients in this study had moderate disease (73.1\%) and almost all patients improved with the use of either topical or topical plus systemic treatment. The majority of the patients (93.4\%) received systemic treatment in combination with topical treatment. One patient $(0.4 \%)$ was reported not to have not improved, and 5 patients $(2.1 \%)$ defaulted from follow-up and their outcome could therefore not be recorded. As has been demonstrated in many previous studies, ${ }^{[13,14,16,21]}$ our patients suffered significant sequelae once their acne had resolved. PIH was a frequent finding (81.0\%), as in previous studies that have shown prevalences of PIH of $65-75 \%$ in black patients. ${ }^{[13-16,18]}$ In a study by Perkins et al., ${ }^{[1]}$ African American patients were found to have a higher prevalence of dyspigmentation and scarring than their white counterparts. This finding has also been reported by others. ${ }^{[17,22-26]} \mathrm{PIH}$ has been rated as the most troublesome sequela experienced by black patients following inflammatory acne, in contrast to white patients, among whom scarring is more common. . $^{[7,23,27-29]}$

\section{Study limitations}

Although the findings of the current study outline the characteristics of acne in black patients, it has certain limitations. These include the use of patient records from only two private sector health facilities, which may not be representative of the entire Durban region. Also, patients aged $<18$ years were excluded from the study. A comparison between various ethnic groups would also have been useful. Finally, the study was retrospective and the findings may need to be validated by a prospective study in the future.

\section{Conclusion}

This study of black patients in Durban, SA, shows that acne mainly affects young females. This finding may be due to females being more likely to seek medical attention for this cosmetically disturbing disorder. In terms of severity, the majority of patients had mild or moderate acne, with inflammatory acne being the most common subtype. The most significant sequela is $\mathrm{PIH}$, with $>80 \%$ of patients affected.

Early recognition of acne and prompt and aggressive therapy are important, and may minimise complications and reduce the cost of treatment.

Acknowledgements. Author TPZ sincerely thanks Prof. N C Dlova for giving her permission to access and use her patient data records, Dr T Mabaso for allowing her to use his premises, and Miss Mpume Luthuli and Miss Xoliswa Ngubeni for assisting with retrieval of data.

Author contributions. All the authors participated in data collection, data analysis and interpretation, drafting the article, revision of the article and final version of the article to be published.

Funding. None.

Conflicts of interest. None.

1. Perkins AC, Cheng CE, Hillebrand GG, Miyamoto K, Kimball AB. Comparison of the epidemiology of acne vulgaris among Caucasian, Asian, Continental Indian and African American women. J Eur Acad Dermatol Venereol 2010;25(9):1054-1060. https://doi.org/10.1111\%2Fj.1468-3083.2010.03919.x Healy E, Simpson N. Fortnightly Review: Acne vulgaris. BMJ 1994;308(6932):831-833. https://doi org $/ 10.1136 \% 2 \mathrm{Fbmj} .308 .6932 .831$

3. Hanna S, Sharma J, Klotz J. Acne vulgaris - more than skin deep. Dermatol Online J 2003;9(3):8. http:// escholarship.org/uc/item/0t2870v9 (accessed 30 September 2017)

4. Mosam A, Vawda NB, Gordhan AH, Nkwanyana N, Aboobaker J. Quality of life issues for South Africans with acne vulgaris. Clin Exp Dermatol 2005;30(1):6-9. https://doi.org/10.1111\%2Fj.13652230.2004.01678.x

5. Davis EC, Callender VD. A review of acne in ethnic skin: Pathogenesis, clinical manifestations, and management strategies. J Clin Aesthet Dermatol 2010;3(4):24-38.

6. Dlova NC, Mankahla A, Madala N, Grobler A, Tsoka-Gwegweni J, Hift RJ. The spectrum of skin diseases in a black population in Durban, KwaZulu-Natal, South Africa. Int J Dermatol 2014;54(3):279285. https://doi.org/10.1111\%2Fijd.12589

Taylor SC, Cook-Bolden F, Rahman Z, Strachan D. Acne vulgaris in skin of color. J Am Acad Dermatol 2002;46(2):S98-S106. https://doi.org/10.1067\%2Fmjd.2002.120791

8. Nnoruka E, Okoye O. Topical steroid abuse: Its use as a depigmenting agent. J Natl Med Assoc 2006:98(6):934-939.

IndexMundi. South Africa Demographics Profile 2017. http://www.indexmundi.com/south_africa/ demographics_profile.html (accessed 30 October 2017).

10. Jappe U. Pathological mechanisms of acne with special emphasis on Propionibacterium acnes and related
. therapy. Acta Derm Venereol 2003;83(4):241-248. https://doi.org/10.1080\%2F00015550310016463

11. Callender VD. Acne in ethnic skin: Special considerations for therapy. Dermatol Ther 2004;17(2):184195. https://doi.org/10.1111\%2Fj.1396-0296.2004.04019.x

12. Dréno B. Recent data on epidemiology of acne. Ann Dermatol Venereol 2010;137(12):3-5. https://doi org/10.1016\%2Fs0151-9638\%2810\%2970045-4

13. White GM. Recent findings in the epidemiologic evidence, classification, and subtypes of acne vulgaris J Am Acad Dermatol 1998;39(2):S34-S37. https://doi.org/10.1016\%2Fs0190-9622\%2898\%2970442-6 4. Berardesca E, Maibach H. Ethnic skin: Overview of structure and function. J Am Acad Dermatol 2003;48(6):S139-S142. https://doi.org/10.1067\%2Fmjd.2003.273

15. Rzany B, Kahl C. Epidemiology of acne vulgaris. J Dtsch Dermatol Ges 2006;4(1):8-9. https://doi. org/10.1111\%2Fj.1610-0387.2005.05876.x

16. Rawlings AV. Ethnic skin types: Are there differences in skin structure and function? Int J Cosmet Sci 2006;28(2):79-93. https://doi.org/10.1111\%2Fj.1467-2494.2006.00302.x

17. Hengge UR, Ruzicka T, Schwartz RA, Cork MJ. Adverse effects of topical glucocorticosteroids. J Am Hengge UR, Ruzicka T, Schwartz RA, Cork MJ. Adverse effects of topical gluco
Acad Dermatol 2006;54(1):1-15. https://doi.org/10.1016\%2Fj.jaad.2005.01.010

18. Kligman AM, Mills OH. Acne cosmetica. Arch Dermatol 1972;106(6):843-850. https://doi.org/10.10
Acad 01\%2Farchderm.106.6.843 
19. Taylor SC, Cook-Bolden F, Rahman Z, Strachan D. Acne vulgaris in skin of color. J Am Acad Dermatol 2002;46(2 Suppl):S98-S106. https://doi.org/10.1067\%2Fmjd.2002.120791

20. Dlova NC, Mankahla A, Madala N, Grobler A, Tsoka-Gwegweni J, Hift RJ. The spectrum of skin diseases in a black population in Durban, KwaZulu-Natal, South Africa. Int J Dermatol 2014;54(3):279diseases in a black population in Durban,
285. https://doi.org $/ 10.1111 \% 2 \mathrm{Fijd} .12589$

21. Goulden V, Clark SM, Cunliffe WJ. Post-adolescent acne: A review of clinical features. Br J Dermatol 1997;136(1):66-70. https://doi.org/10.1046\%2Fj.1365-2133.1997.d01-1144.x

22. Araviiskaia E, Dréno B. The role of topical dermocosmetics in acne vulgaris. J Eur Acad Dermatol Venereol 2016;30(6):926-935. https://doi.org/10.1111\%2Fjdv.13579

. Degitz K, Placzek M, Borelli C, Plewig G. Pathophysiology of acne. J Dtsch Dermatol Ges 2007;5(4):316-323. https://doi.org/10.1111\%2Fj.1610-0387.2007.06274.X

4. Halder RM, Brooks HL, Callender VD. Acne in ethnic skin. Dermatol Clin 2003;21(4):609-615. https://doi.org/10.1016\%2Fs0733-8635\%2803\%2900082-2

25. Child, Fuller, Higgins, Du Vivier. A study of the spectrum of skin disease occurring in a black population in south-east London. $\mathrm{Br}$ J Dermatol 1999;141(3):512-517. https://doi.org/10.1046\%2Fj.13652133.1999 .03047$.
26. Stathakis V, Kilkenny M, Marks R. Descriptive epidemiology of acne vulgaris in the community. Australas J Dermatol 1997;38(3):115-123. https://doi.org/10.1111\%2Fj.1440-0960.1997.tb01126. Pochi PE Strauss IS. Sebaceous gland activity in black skin. Dermatol Clin 1988:6(3):349-351.

28. La Ruche G, Cesarini JP. Histology and physiology of black skin. Ann Dermatol Venereol 1992;119(8):567-574

29. Dressler C, Rosumeck S, Nast A. How much do we know about maintaining treatment response after successful acne therapy: Systematic review on the efficacy and safety of acne maintenance therapy. Dermatology 2016;232(3):371-380. https://doi.org/10.1159\%2F00044606 